\title{
ON THE ESTIMATION OF PARAMETERS OF THICK CURRENT SHELL MODEL OF EQUATORIAL ELECTROJET USING OPTIMISATION METHOD
}

\author{
A.B. Rabiu ${ }^{1,2}$ and N. Nagarajan ${ }^{1}$ \\ ${ }^{1}$ National Geophysical Research Institute, Uppal road, Hyderabad 500 007, INDIA. \\ ${ }^{2}$ Space Physics Lab., Dept. of Physics, Federal University of Technology, Akure, Nigeria
}

\begin{abstract}
Equatorial electrojet, an intense current flowing eastward in the low latitude ionosphere within the narrow region flanking the dip equator, is a major phenomenon of interest in geomagnetic field studies. For the first time the five parameters required to fully describe the Onwumechili's composite thick current shell model format of equatorial electrojet have been evaluated from a single autonomous set of ground data at solar minimum. The non-linear model was applied to four data points, each with a pair of simultaneously measured horizontal $H$ and vertical $Z$ variation field components. The resultant system of eight non-linear equations with five unknown model parameters were subjected to non-linear least square optimisation method taking advantage of the robust Levenberg-Madquart optimisation subroutine of licensed MATLAB 6.0 version. The thick current shell format model parameters estimated for Indian sector are shown to be within the appropriate limits and in excellent agreement with literature and physical expectation.
\end{abstract}

Keywords: Equatorial electrojet; Numerical models; Optimisation

\section{INTRODUCTION}

Modeling the ionosphere and its current systems has continued to gain attention (Jadhav et al., 2002; Doumoya et al., 2003; Holme et al., 2004) due to its increasing significance in the earthsatellite communication, applications in space weather studies and source field problems in magnetotellurics. The daytime dynamo E region of the ionosphere in the neighbourhood of magnetic dip equator have been identified to consist of two layers of currents responsible for the quiet solar daily variations; one known as the worldwide Sq, flowing at an altitude of (118 \pm 7$)$ $\mathrm{km}$, the other one is the intense non-uniform east west current named as equatorial electrojet, EEJ, by Chapman (1951), which flows at a lower altitude of $(106 \pm 2) \mathrm{km}$ (Chapman, 1951; Richmond, 1973; Rastogi, 1975; Onwumechili, 1997).

Since Chapman (1951) presented the first model of equatorial electrojet, EEJ, a number of models have been proposed (Onwumechili, 1966a, b, c; 
Untiedt, 1967; Richmond, 1973; Suzuki, 1973; Fambitakoye and Mayaud, 1976). Onwumechili (1966a, b, c; 1967) presented a two dimensional model of the continuous current distribution responsible for EEJ as:

$j=j o a^{2}\left(a^{2}+a x^{2}\right) b^{2}\left(b^{2}+b z^{2}\right) /\left(a^{2}+x^{2}\right)^{2}\left(b^{2}+z^{2}\right)^{2}$ (1)

Where $j\left(\mu \mathrm{A} \mathrm{m}{ }^{-2}\right)$ is the eastward current density at the point $(x, z)$. The origin is at the centre of the current, $x$ is northwards, and $z$ is downwards. The model is extensible to three dimension by introducing the coordinate $y$ or longitude $\varnothing$ or eastwards local time $t . j_{0}$ is the current density at the centre, $a$ and $b$ are constant latitudinal and vertical scale lengths respectively, $a$ and $b$ are dimensionless parameters controlling the current distribution latitudinally and vertically respectively. It is a meridional plane model, which in this simple form has to be applied to specific longitudes or local times. Once the five (5) parameters $j_{o}, a, a, b, b$ are determined by fitting observational data, a number of physical parameters of the current and its magnetic field can be calculated from them. The model is a realistic model having both width and thickness.

Onwumechili (1966c) used the Biot-Savart law to obtain the northwards $\mathrm{X}$ and vertical $\mathrm{Z}$ components of the magnetic field variation with latitude on the horizontal plane $(v=$ constant $)$ as a result of the current distribution in (1) as follows:

$$
\begin{aligned}
& \text { (sg. z) } \begin{array}{r}
P^{4} X=1 / 2 k\left[(1+b)(v+a v+2 a a)(u+b)^{2}\right. \\
+2(1-b)(v+a v+4 a-2 a a)(u+b) \\
\left.+(1+b)(v+a v+2 a)(v+a)^{2}\right]
\end{array} \\
& \begin{array}{r}
-(\operatorname{sg} x) P^{4} Z=1 / 2 k\left[(1+a)(1+b)(u+b)^{3}+\left((1+a)(1+b)(u+b)^{2}\right.\right. \\
+(1+b)(v+a v+3 a-a a)(v+a)(u+b) \\
-(1-b) b(v+a v+3 a-a a)(v+a)]
\end{array}
\end{aligned}
$$

$$
\begin{aligned}
& \text { Where } \begin{array}{l}
P^{2}=(u+b)^{2}+(v+a)^{2} \\
k=0.1 \pi^{2} a b j_{0} \\
u=/ x / \text { and } v=/ z / \\
\text { sg. } x=\text { sign of }(x / u) \text { and } \text { is } \pm 1 \text { when } x=0 \\
\text { sg.z }=\text { sign of }(z / v) \text { and } i s \pm 1 \text { when } z=0
\end{array}
\end{aligned}
$$

Equations 2 and 3 give the horizontal and vertical magnetic field variations respectively, due to thick current shell format.

With some simplifying assumptions, the thick current shell format represented by equations 2 and 3 were approximated to give the horizontal and vertical magnetic field variations respectively, due to thin current shell format as:

(sg. z) $P^{4} X=1 / 2 K a\left[(v+a v+2 a a)(u+b)^{2}+(v+a v+2 a)(v+a)^{2}\right]$
- (sg.x) $P^{4} Z=1 / 2 K a(u+b)\left[(1+a)(u+b)^{2}+(v+a v+3 a-a a)(v+a)\right]$

where;

$$
\begin{aligned}
\mathrm{K} & =0.2 \pi J_{0} \\
\text { Or } \quad \mathrm{Ka} & =k(1+b)
\end{aligned}
$$

\footnotetext{
${ }^{2}$ Corresponding author: Dr. A. B. Rabiu, Space Physics Lab., Department of Physics, Federal University of Technology, Akure, NIGERIA. Tel.: +234 8030705787; E-mail address: tunderabiu@yahoo.com
}

2 Journal of Science and Technology, Vol. 28, No. 3, Dec., 2008 
$\mathrm{K}$ is the magnetic field, being the magnetic field of an infinite plane current sheet with constant intensity $\mathrm{J}_{0} \mathrm{~A} \mathrm{~km}^{-1}$. It should be noted that $b$, the parameter that controls the vertical scale of the current is conspicuously missing in the thin shell format field equations 9 and 10 .

In the neigbourhood of dip equator northwards component $\mathrm{X}$ and horizontal component $\mathrm{H}$ are approximately equal as the inclination is very small, therefore $\Delta \mathrm{X} \approx \Delta \mathrm{H} . \Delta \mathrm{Z}$ and $\Delta \mathrm{H}$ are measurable field components at observatories, where $v$ is the current altitude taken to be $106 \mathrm{~km}$ $\left(0.96^{\circ}\right)$ as determined by rocket and satellite measurements (Onwumechili, 1997), $u$ is the dip latitude of the point of observation.

The advantages of Onwumechili's model over others have been identified in Onwumechili (1997). The current distribution of Onwumechili (1966a, b, c) model, henceforth designated as OM66, has been used by several authors to model equatorial electrojet, for examples Onwumechili and Agu (1989), Onwumechili and Ezema (1992), Oko et al., (1966), Rigoti et al., (1999), Jadhav et al., (2002). The simplification of OM66 into measurable magnetic field components necessary for evaluation of model parameters resulted in two current shell formats, one known as the thick current shell format and the other known as thin current shell format. The latter is the approximation of the former. With the exception of Onwumechili and Ezema (1992) who applied the OM66 in its thick current shell format to POGO satellite data, all others have used the approximation known as the thin shell format. Onwumechili and Ogbuehi (1967) and Onwumechili et al., (1989) used satellite data to evaluate three parameters $K, a$, and $a$ from the thin shell format; Onwumechili and Ezema (1992) employed the POGO satellite data to evaluate the five parameters using the thick current shell format; Oko et al., (1996) evaluated only three parameters $j_{o}$ (obtainable from $K$ or $k), a, a$, using the thin current shell format; Rigoti et al., (1999) evaluated three model parameters $j_{o}, a, a$, for Brazilian sector using the thin current shell format with a set of ground data; Jadhav et al., (2002) also employed the thin current shell format using Oersted satellite data between April 1999 and March 2000 to evaluate three parameters $K, a$, and $a$. Electrojet models computed under the thin-shell approximation have been shown to be inadequate by Untiedt (1967), Sugiura and Poros (1969), and Richmond (1973) due to the neglect of vertical currents.

It is observed that the thick current shell of OM66 employed by Onwumechili and Ezema (1992) was evaluated at high solar activity period, 1967 to 1969 , and results were published only for 1100 and 1200 hours local time. Even then it is interesting to see the cumbersome nature of their long analytical process of evaluation, of the parameters using satellite data, which necessitated some approximations. Onwumechili (1997) highlighted the many successes of his continuous current distribution over the years and noted that the five model parameters have never been obtained from a single autonomous set of ground data using the thick current shell format. The thick current shell format of the model, which takes into account both the width and the thickness of the jet, contains all the five parameters in a non-linear form that makes it complicated for trivial attempt. It is a composite format capable of describing in detail the latitudinal and vertical flow of EEJ. The primary objective of this work is to evaluate the five (5) parameters that completely define the continuous current distribution of Equatorial electrojet from a single set of ground data during low solar activity for the first time, and generate the daytime hourly profiles of the parameters.

\section{METHODOLOGY}

A look at equations 2 and 3 reveals that each of $\mathrm{H}$ and $\mathrm{Z}$, which are measurable quantities at magnetic observatories are expressed in terms of $k, a, a, b$, and $b$, as well as $v$ and $u$. The first five parameters ( $k, a, a, b$, and $b$ ) are the model parameters while $u$ and $v$ are known values at any point of observation. Rewriting equations 2 and 3 such that: 


$$
\begin{gathered}
\text { (sg. z) } P^{4} X-1 / 2 k\left[(1+b)(v+a v+2 a a)(u+b)^{2}+2(1-b)(v+a v+4 a-2 a a)(u+b)\right. \\
\left.+(1+b)(v+a v+2 a)(v+a)^{2}\right]=0 \\
-(\operatorname{sg} . x) P^{4} Z-1 / 2 k\left[(1+a)(1+b)(u+b)^{3}+\left((1+a)(1+b)(u+b)^{2}+(1+b)(v+a v+3 a-a a)\right.\right. \\
(v+a)(u+b)-(1-b) b(v+a v+3 a-a a)(v+a)]=0
\end{gathered}
$$

Implies that a non linear function $\mathrm{F}(k, a, a, b, b)$ of magnetic field variations in each of the components $\mathrm{X}$ and $\mathrm{Z}$ can be written such that

$\mathrm{F}(k, a, a, b, b)=0$

For each hour, we applied equations 13 and 14 to a set of simultaneously derived electrojet index pairs $\mathrm{H}_{\mathrm{i}}$ and $\mathrm{Z}_{\mathrm{i}}$ for a set of four data stations each at dip latitude $u_{i}(i=1-4)$, so we have a set of eight (8) non linear simultaneous equations. Hence the model parameters are overdetermined.

\section{Data preparation/smoothing}

Simultaneously recorded hourly horizontal $\mathrm{H}$ and vertical $\mathrm{Z}$ field values were obtained from 5 stations whose coordinates are shown in Table 1. These hourly horizontal and vertical field values were treated for hourly departures, non-cyclic and storm-time disturbance, Dst, variations to ensure absolute quiet condition as required. The electrojet index was obtained by subtracting the hourly values of worldwide solar quiet daily variation, Sq, as obtained at Hyderabad, a station just outside of electrojet, from other four stations that fall within the electrojet influence.

The current distribution described an external field and so it became necessary to separate the internal field from the external field. It is known that the observed values of $\mathrm{H}$ and $\mathrm{Z}$ are algebraic sum of the external ionospheric current and internal effects, such that:

$\Delta \mathrm{H}_{\mathrm{e}}+\Delta \mathrm{H}_{\mathrm{i}}=\Delta \mathrm{H}$
$\Delta \mathrm{Z}_{\mathrm{e}}-\Delta \mathrm{Z}_{\mathrm{i}}=\Delta \mathrm{Z}$

Onwumechili (1997, page 128) reported the ratios of $0.28 \pm 0.08$ and $-0.17 \pm 0.02$ for $\Delta \mathrm{H}_{\mathrm{i}} / \Delta \mathrm{H}_{\mathrm{e}}$ and $\Delta \mathrm{Z}_{\mathrm{i}} / \Delta \mathrm{Z}_{\mathrm{e}}$ respectively found in excellent agreement with Davis et al., (1967) result. We used these ratios to filter out the internal field from the observed values such that $\Delta \mathrm{H}$ and $\Delta \mathrm{Z}$ reflect the variation field due to external source of interest, the ionosphere. We therefore generated a hourly profiles of EEJ index in $\mathrm{H}$ and $\mathrm{Z}$ due to external current system of equation 1 for selected 60 quiet days of the solar minimum year 1986 (Sunspot number $\mathrm{R}=13.4$ ).

\section{Levenberg-Marquardt Method}

The Levenberg-Marquardt (LM) method (Levenberg, 1944; Marquardt, 1963; Shepherd, 1997; Press et. al., 1992) is an advanced, and the most widely used, non-linear optimisation algorithm which significantly outperforms simple gradient descent and other conjugate gradient methods in a wide variety of problems. It works very well in practice and has become the standard of non-linear least squares routines (Press et al., 1992). LM method is widely presented in

Table 1: Coordinates of the geomagnetic observatories

\begin{tabular}{llrcc}
\hline Station & Code & \multicolumn{2}{c}{ Geog. } & Dip latitude \\
& & Lat. $\mathbf{N}^{\circ}$ & \multicolumn{1}{c}{ long ${ }^{\circ} \mathbf{E}$} & \multicolumn{1}{c}{$\left.{ }^{\circ} \mathbf{N}\right)$} \\
\hline Trivandrum & TRD & 8.29 & 76.57 & 0.20 \\
Ettaiyapuram & ETT & 9.10 & 78.00 & 0.50 \\
Kodaikanal & KOD & 10.23 & 77.47 & 2.14 \\
Annamalainagar & ANN & 11.4 & 79.7 & 3.28 \\
Hyderabad & HYB & 17.42 & 78.55 & 9.33 \\
\hline
\end{tabular}

4 Journal of Science and Technology, Vol. 28, No. 3, Dec., 2008 
More (1977), Bates and Watts (1981), Gill et al., (1981) and Bishop (1995).

LM finds the minimum of a function $F(x)$ which is a sum of squares of non-linear functions:

$$
\mathbf{F}(\mathrm{x})=\frac{1}{2} \Sigma_{i}\left[f_{i}(x)\right]^{2}
$$

Where $\mathrm{x}=\left(\mathrm{x}_{1}, \mathrm{x}_{2}, \ldots . \mathrm{x}_{\mathrm{n}}\right)$ is a vector, in our case $\mathrm{n}=8$.

The LM method employs a search direction that is a solution of the linear set of equations:

$\left.\left[\int\left(x_{k}\right)^{T}\right]\left(x_{k}\right)+\lambda_{k}\right] d_{k}=-\int\left(x_{k}\right) F\left(x_{k}\right)$

Where $\mathrm{J}_{\mathrm{i}}\left(\mathrm{x}_{\mathrm{k}}\right)$ is the Jacobian of $\mathrm{f}_{\mathrm{i}}(\mathrm{x}) ; \lambda_{\mathrm{k}}$ are nonnegative scalars that control the magnitude and direction $d_{k}$, and $I$ is the identity matrix. When $\lambda_{k}$ is zero, the direction $d_{k}$ is identical to that of the Gauss-Newton method. As $\lambda_{k}$ tends to infinity, $\mathrm{d}_{\mathrm{k}}$ tends toward a vector of zeros and a steepest descent direction. LM method is a blend of gradient descent and Gauss-Newton iteration. LM also demonstrates an increased robustness over Gauss-Newton method.

The MATLAB algorithm for LM implementation is described in detail in the Optimisation toolbox user guides by Mathworks (2000). LM algorithm is the default method used by LSQNONLIN of MATLAB for medium scale algorithm and the Jacobian is computed by default using finite differencing. By default LSQNONLIN chooses the large-scale algorithm which is a subspace trust region method based on the interior-reflective Newton method. LSQNONLIN with 'options.LargeScale' set to "off" uses the medium scale algorithm with the LM method with line search by default.

The optimisation algorithm of MATLAB 6.0 employs a pair of files in same directory. The first step entailed the development of an M-file that computes the values of objective function (equation 15). The second step called the non- linear least squares routine of MATLAB with an appropriate starting guess $\mathrm{x}_{0}$ and option.

The statement:

Option $=$ optimset ('LargeScale', 'off')

Suppresses the default Large Scale subroutine and favours LM algorithm

The statement:

$x=$ LSQNONLIN(@modelfun, $x_{0}$,option)

invokes the optimixer which makes use of the LM as subroutine. LM computes Jacobian matrices by finite difference technique for default estimation. LSQNONLIN solves problems of the form:

$$
\min \sum_{i}\left[f_{i}(x)\right]^{2}
$$

$\min \sum\left[\mathrm{f}_{\mathrm{i}}(\mathrm{x})\right]^{2}$

where $x$ and the values returned by $\mathrm{f}_{\mathrm{i}}(\mathrm{x})$ can be vectors or matrices.

LSQNONLIN(@modelfun, $x_{0}$, option) starts at the matrix $\mathrm{x} 0$ and finds a minimum $x$ to the sum of squares of the functions in modelfun. It tends to optimize $\mathrm{f}(\mathrm{x})$ and obtain the vector $x$, a matrix whose elements are the five model parameters that satisfies $\mathrm{f}(\mathrm{x})$ as represented in equation 15 . Modelfun is the name of M-File that accepts input $x$ and returns a vector (or matrix) of function values $F$ evaluated at $\mathrm{x}$.

We found it necessary to normalize the equations such that the output of the program gives the results in order of unity, this is emphasized by Press et al., (1992). One outstanding performance we observed is that with appropriate starting values of iteration, which we simply chose to be within the range of values available in the literature, the program does not need any constraint. Rather it optimized to give the result we obtained.

We estimated the model parameters at every hour and take the seasonal means according to 
Llyod's classification: E-season (March, April, August) and D-season (November, December, September, October), J-season (May, June, July, January, February).

Table 2: Daytime Seasonal and annual means of the evaluated model parameters with their standard deviations (SD)

\begin{tabular}{|c|c|c|c|c|}
\hline \multirow{2}{*}{ Parameters } & \multicolumn{3}{|c|}{ Seasons } & \multirow{2}{*}{ Annual } \\
\hline & $\mathbf{E}$ & $\mathbf{J}$ & D & \\
\hline$k(100 \mathrm{~A})$ & 101.8027 & 97.4532 & 98.5170 & 99.2576 \\
\hline SD & 9.8734 & 6.2797 & 6.7001 & 7.0749 \\
\hline$a\left(^{\circ}\right)$ & 3.6879 & 3.6828 & 3.6833 & 3.6874 \\
\hline SD & 0.0081 & 0.0077 & 0.0074 & 0.0073 \\
\hline$a$ & -1.8171 & -1.9620 & -1.8588 & -1.8793 \\
\hline SD & 0.3827 & 0.2303 & 0.2543 & 0.2628 \\
\hline$b\left(^{\circ}\right)$ & 0.0778 & 0.0796 & 0.0790 & 0.0788 \\
\hline SD & 0.0047 & 0.0030 & 0.0032 & 0.0034 \\
\hline$b$ & 0.4874 & 0.5019 & 0.4970 & 0.4954 \\
\hline SD & 0.0375 & 0.0240 & 0.0256 & 0.0270 \\
\hline
\end{tabular}

Table 3: Annual mean hourly values of the parameters using thick current shell model

\begin{tabular}{crrrrc}
\hline Local time $(\mathrm{hrs})$ & $k(100 \mathrm{~A})$ & $a\left(^{\circ}\right)$ & $a$ & $b\left(^{\circ}\right)$ & $b$ \\
\hline 0700 & 90.1789 & 3.6731 & -2.1531 & 0.0827 & 0.5267 \\
0800 & 94.2770 & 3.6795 & -2.0014 & 0.0808 & 0.5113 \\
0900 & 101.7332 & 3.6867 & -1.7078 & 0.0771 & 0.4818 \\
1000 & 107.5295 & 3.6905 & -1.5168 & 0.0747 & 0.4627 \\
1100 & 109.3809 & 3.6943 & -1.5206 & 0.0739 & 0.4564 \\
1200 & 107.3849 & 3.6924 & -1.6123 & 0.0750 & 0.4655 \\
1300 & 103.7775 & 3.6907 & -1.7614 & 0.0770 & 0.4804 \\
1400 & 99.0073 & 3.6874 & -1.9540 & 0.0794 & 0.4998 \\
1500 & 94.8184 & 3.6830 & -2.1069 & 0.0813 & 0.5152 \\
1600 & 92.5686 & 3.6793 & -2.1859 & 0.0823 & 0.5232 \\
1700 & 91.1776 & 3.6743 & -2.1522 & 0.0827 & 0.5266 \\
Mean & 99.2576 & 3.6847 & -1.8793 & 0.0788 & 0.4954 \\
SD & 7.0749 & 0.0073 & 0.2628 & 0.0034 & 0.0270 \\
\hline
\end{tabular}

Table 4: Comparison of noontime means of evaluated model parameters with available piecewise data from literature for Indian sector

\begin{tabular}{|c|c|c|c|c|c|c|}
\hline & \multirow[b]{2}{*}{$\begin{array}{l}\text { Source (model } \\
\quad \text { format) }\end{array}$} & \multicolumn{5}{|c|}{ Model parameters } \\
\hline & & $\begin{array}{c}\boldsymbol{k}^{k} \\
\mathrm{SD}(\mathrm{Amp})\end{array}$ & $\begin{array}{c}\boldsymbol{a} \\
\mathrm{SD}\left(^{\circ}\right)\end{array}$ & $a$ & $\begin{array}{c}\boldsymbol{b} \\
\mathrm{SD}\left({ }^{\circ}\right)\end{array}$ & $b$ \\
\hline \multirow[t]{2}{*}{ Our result } & Ground data (thick) & 10738 & 3.692 & -1.61 & 0.075 & 0.466 \\
\hline & & 313 & 0.003 & 0.12 & 0.001 & 0.009 \\
\hline Onwumechili and & Satellite data (thin) & & 4.270 & -1.59 & & \\
\hline Ogbuehi (1967) & & & 1.04 & 0.08 & & \\
\hline Onwumechili et al. & Satellite data (thin) & & 2.937 & -1.86 & & \\
\hline 1989 & & & 0.171 & 0.06 & & \\
\hline Onwumechili and & Satellite data (thick) & 17282 & 3.342 & -1.53 & 0.079 & 0.526 \\
\hline Ezema (1992) & & 1319 & 0.081 & 0.08 & 0.001 & 0.018 \\
\hline \multirow[t]{2}{*}{ Oko et al. 1996} & Ground data (thin) & & 3.570 & -1.56 & & \\
\hline & & & 0.040 & 0.02 & & \\
\hline
\end{tabular}

6 Journal of Science and Technology, Vol. 28, No. 3, Dec., 2008 


\section{RESULTS AND DISCUSSION}

Seasonal and annual means of the evaluated model parameters $k, a, a, b, b$ for the Indian sector are displayed in Table 2 with their standard deviations. These seasonal values have no basis for comparison in literatures as only noontime values of $a(-1.58 \pm 0.01)$ and $a(3.53 \pm 0.04)$ were reported for equinox noontime by Oko $e t$ $a l .$, 1996. Rather most literatures including Onwumechili (1997) discussed the seasonal variations of the derived parameters, from this model, which of course are of interest to the geophysical society. Table 3 presents the mean annual hourly values of the model parameters for daytime (hours 0700 to 1700).

Table 4 compares noontime model parameters from our work with the available ones in the literature, indicating the data source (ground or satellite) and the type of current shell format employed. Obviously the thin current shell format permits direct evaluation of only the latitudinal parameters $a$, $a$, and an implicit function of current density $\mathrm{j}_{0}$ in terms of the magnetic constant $K$ which is not shown in Table 4 . The values of $a, a, b$, and $b$ compare so well with the existing values as they all fall within the appropriate limits of standard deviations. The value of $b$ as measured by satellite and adopted for so long as $(8.5 \pm 0.5) \mathrm{km}$ (Onwumechili, 1997) equivalent of $\left(0.0767 \pm 0.0045^{\circ}\right)$ is in excellent agreement with our value $\left(0.0778 \pm 0.0047^{\circ}\right)$. The significant variation in our own parameter $k$ $(10738 \pm 313)$ Amp and the only available basis for comparison, that of Onwumechili and Ezema (1992), (172383 \pm 1319$)$ Amp can be accounted for by the solar activity difference in the periods of data acquisition. Model parameter $k$ by definition is directly proportional to the current density (see equation 5). We estimated the parameter for low solar activity period (sunspot number = 13.4), while Onwumechili and Ezema, (1992) considered high solar activity period (average sunspot number $=101.7)$ using available satellite data and analytical procedure. Oko et al., (1996) estimated thin current shell parameters for low solar activity period $(\mathrm{R}=13.4)$ and obtained lower current density than Onwumechili and Ezema, (1992).

We estimated the magnetic constant, $K$, expressed by definition (Onwumechili, 1997) as:

$$
k=\frac{k(1+\beta)}{\alpha}
$$

And obtained the correlation coefficient and the probability of significance, between our estimated magnetic constant $\mathrm{K}_{\mathrm{rn}}$ from our thick current shell and that of Oko et al., (1996) $\mathrm{K}_{\mathrm{o}}$ obtained directly from thin current shell format, using the syntax:

$$
[\mathrm{R}, \mathrm{P}]=\operatorname{CORRCOEF}\left(\mathrm{K}_{\mathrm{rn}}, \mathrm{K}_{\mathrm{o}}\right)
$$

Where $\mathrm{R}$ is the correlation coefficient and $\mathrm{P}$ returns the probability of getting a correlation as large as the observed value by random chance, when the true correlation is zero. If $\mathrm{P}$ is small, say less than 0.05 , then the correlation $\mathrm{R}$ is significant.

We obtained a high positive correlation coefficient of 0.9903 and $p$-value of $4.9 \times 10^{-9}(<<0.05)$. This demonstrates a high level of significance and gives credence to our estimation using the approach we have taken. It is sufficient to mention that the other landmark and current parameters of EEJ derived from these 5 model parameters are quite in agreement with literature and physical expectation.

\section{CONCLUSION}

The five parameters that fully described the current distribution of EEJ have been evaluated from an autonomous set of ground data. This was accomplished by a computer program based on the Levenberg-Marquardt least square method. The program consisted of a pair of Mfile and the execution file that invoke the state of the art optimisation of licensed MATLAB 6.0 version. The results obtained compare well with earlier piecewise obtained parameters. The mean noontime values of the model parameters $k, a, a$, $b$, and $b$, are $(10738 \pm 313) \mathrm{A},(3.6924 \pm$ 
$0.0023)^{\circ}, \quad(-1.6123 \pm 0.1169), \quad(0.0750 \pm$ $0.0012)^{\circ}$, and $(0.4655 \pm 0.0091)$ respectively. The highly significant correlation of 0.99 and estimated $\mathrm{p}$ value of $4.9 \times 10^{-9}$ which is much less than 0.05 between the values of our derived magnetic constant $K$ and those obtained directly from thin shell format by Oko et al., (1996) demonstrated excellent agreement between our parameters and their data.

Most importantly we have demonstrated that with a simple algorithm and appropriate computer code, a more suitable model can be applied to anomalous equatorial geomagnetic phenomena in a bid to explain its detailed feature and thus produce a more reliable and excellent composite model description.

\section{ACKNOWLEDGEMENTS}

Data for Trivandrum TRD, Kodaikanal KOD, Annamalainagar ANN, and Hyderabad HYB were obtained from http://swdcwww.kugi.kyotou.ac.jp/hyplt/, courtesy World Data Centre-C2, Kyoto University, Kyoto, Japan. Data for Ettaiyapuram ETT and the permission to publish this work were obtained from the Director, National Geophysical Research Institute (NGRI), Hyderabad, India. One of us (ABR) thanks Third World Academy of Sciences TWAS, Trieste, Italy, and CSIR (Government of India) for awarding Postdoctoral Research Fellowships. The authors are grateful for the technical discussion held with Dr. D. V. Ramana of NGRI at the onset of this work.

\section{REFERENCES}

Bates, D. M. and Watts, D. G. (1988). Nonlinear Regression and Its Applications. Wiley. New York.

Bishop, C. M. (1995). Neural networks for pattern recognition. Clarendon Press, Oxford.

Chapman, S. (1951). The equatorial electrojet as deduced from the abnormal current distribution above Huancayo and elsewhere. Archiv Fuer Meteorologie, Geophysik und Bioklimatologie. Serie A 4: 368-390.
Davis, T. N., Burrows, K., and Stolarik, J. D. (1967). A latitude survey of the equatorial electrojet with rocket-borne magnetometer, J. Gephys. Research., 72: 1845-1861.

Doumouya, V., Cohen, Y., Arora, B. R., Yumoto, K. (2003). Local time and longitude dependence of the equatorial electrojet magnetic effects. J. Atmos. Solar-Terr. Phys. 65: 1265-1282.

Fambitakoye, O. and. Mayaud, P.N. (1976). Equatorial electrojet and regular daily variation SR: I. A determination of the equatorial electrojet parameters. J. Atmos. Terr. Phys. 38: 1-17.

Gill, P. R., Murray, W., and Wright, M. H. (1981). The Levenberg-Marquardt method. Practical Optimization. Academic Press, London.

Holme, R., James, M. A., and Luhr, H. (2004). Magnetic field modelling from scalar-only data: Resolving the Backus effect with the equatorial electrojet. Earth Planets Space. 57: $1-8$.

Jadhav, G., Rajaram, M., and Rajaram, R. (2002). A detailed study of equatorial electrojet phenomenon using Ørsted satellite observations, J. Geophys. Research. 107 (A8), 1175. doi: 10.1029/2001JA000183.

Levenberg, K. (1944). A Method for the Solution of Certain Problems in Least Squares. Quart. Appl. Math. 2: 164-168.

Marquardt, D. (1963). An Algorithm for LeastSquares Estimation of Nonlinear Parameters. SIAM J. Appl. Math. 11: 431-441.

Mathworks (2000). Optimization Toolbox User's Guide. MathWorks Inc., MA.

More, J. J. (1977). The Levenberg-Marquardt algorithm: Implementation and theory. In: Ed. G. A. Watson, Lecture Notes in Mathematics, 630. Springer-Verlag, New York.

Oko, S. O., and Ezema, P. O., Onwumechili, C. A. (1996). Geomagnetically quiet day iono-

8 Journal of Science and Technology, Vol. 28, No. 3, Dec., 2008 
spheric currents over the Indian sector - II. Equatorial electrojet currents, J. Atmos. Terr. Phys., 58: 555-564.

Onwumechili, C. A. (1966a). A new model of the equatorial electrojet current, Nigerian J. Sci. 1: 11-19.

Onwumechili, C. A. (1966b). A three dimensional model of density distribution in ionospheric currents causing part of quiet day geomagnetic variations. II Symposium d'aeronomie equatoriale, Special publication of Annales de Geophysique, 157-162.

Onwumechili, C. A. (1966c). The magnetic field of a current model for part of geomagnetic Sq variations. $I I^{e}$ Symposium d'aeronomie equatoriale, Special publication of Annales de Geophysique, 163-170.

Onwumechili, C. A. (1967). Geomagnetic variations in the equatorial zone. In: Eds. Matsushita S. and Campbell, W. H. Physics of Geomagnetic Phenomena. 1: 425-507. Academic press, New York.

Onwumechili, C. A. (1997). The Equatorial Electrojet. Gordon and Breach Science Publishers, Netherlands.

Onwumechili, C. A., and Agu, C.E. (1980). General features of the magnetic field of the Equatorial Electrojet measured by the POGO Satellites. Planet. Space Sci. 28: 1125-1130.

Onwumechili, C. A., Ozoemena P. C., and Agu, C.E. (1989). Landmark values of equatorial electrojet and the magnetic field along a meridian near noon. J. Geomag. Geolectr. 41: 443-459.
Onwumechili, C. A., and Ogbuehi, P.O. (1967). Preliminary results on the equatorial electrojet in India. J. Geomag. Geolectr. 19(1): 1522

Press, W. H., Teukolsky, S. A., Vellerling, W. T. and Flannery, B. P. (1992). Numerical recipes in FORTRAN. Cambridge University Press, Cambridge.

Richmond, A. D. (1973). Equatorial electrojet I. Development of a model including winds and instabilities, J. Atmos. Terr. Phys. 35: 1083-1103.

Rigoti, A., Chamalaun, F. H., Trivedi, N. B. and Padilha, A. L. (1999). Characteristics of the Equatorial Electrojet determined from an array of magnetometers in N-NE Brazil. Earth Planets Space. 51: 115-128.

Shepherd, A. J. (1997). Second-Order Methods for Neural Networks: Fast and Reliable Training Methods for Multi-Layer Perceptrons. Springer-Verlag. New York.

Sugiura, M. and Poros D. J. (1969). An improved model equatorial electrojet with meridional current system. J. Geophys. Research. 74: 4025-4034.

Untiedt, J. (1967). A model of the equatorial electrojet including meridional currents, $J$. Geophys. Research., 72: 5799-5810. 